\title{
Self-Presentational Analysis of the Effects of Incentives on Attitude Change Following Counterattitudinal Behavior
}

\author{
Barry R. Schlenker \\ University of Florida \\ Mark R. Leary \\ Denison University
}

\author{
Donelson R. Forsyth \\ Virginia Commonwealth University \\ Rowland S. Miller \\ Sam Houston State University
}

\begin{abstract}
A self-presentational analysis of the forced compliance setting focuses on the predicament-creating aspects of counterattitudinal actions and on the types of accounting tactics people use to excuse or justify events that threaten their identities before real or imagined audiences. The social meaning of monetary payments that are offered for the performance of counterattitudinal actions should affect the nature of the predicament subjects confront. It was hypothesized that when payment is introduced in a context that increases subjects' concerns about moral evaluation relevant to bribery, a direct relationship should occur between magnitude of payment and attitude change. If payment is introduced in a context that minimizes moral evaluation relevant to bribery, however, an inverse relationship should occur. Three experiments provided support for these hypotheses. In addition, attitude change was enhanced when subjects thought they were presenting their accounts to an audience that had observed their actions. Finally, compared to observers, subjects who had received large payments attempted to redefine them to make them appear more legitimate.
\end{abstract}

Despite the amount of theory and research devoted to understanding the impact of counterattitudinal action on attitudes, one particularly enigmatic problem still exists-understanding the effects of incentives on attitude change following counterattitudinal behavior. Dissonance theory (Festinger, 1957) originally generated the prediction that attitude change should be inversely related to the magnitude of payment offered subjects to perform a counterattitudinal action, a relation-

The present studies were supported by Research Scientist Development Award K02-MH00183-02 from the National Institute of Mental Health and National Science Foundation Grant BNS 77-08182 (both to the first author) and a National Science Foundation predoctoral fellowship to the third author. Thanks are extended to Howard J. Goldman for his able assistance in the first two experiments and Marvin E. Shaw for his helpful comments.

Requests for reprints should be sent to Barry $\mathbf{R}$. Schlenker, Department of Psychology, University of Florida, Gainesville, Florida 32611. ship that has been observed in numerous studies (see Collins \& Hoyt, 1972; Wicklund \& Brehm, 1976). In contrast, incentive theory (see Elms, 1967) held that monetary payments act as both incentives for superior counterattitudinal performance and reinforcers for that performance. The incentive position thus generated the prediction that attitude change should be directly related to payment magnitude, a relationship that also has been revealed in several studies (e.g., Elms, 1967; Rosenberg, 1965).

After an initial confrontation between these approaches, several studies found both the direct and inverse relationship in different conditions of the same experiment (Calder, Ross, \& Insko, 1973; Carlsmith, Collins, \& Helmreich, 1966; Cooper \& Worchel, 1970; Crano \& Messé, 1970; Helmreich \& Collins, 1968; Holmes \& Strickland, 1970; Linder, Cooper, \& Jones, 1967) and led many to conclude that dissonance predictions hold under one set of conditions, and incentive predictions hold under another set. Unfortunately, 
a search for the specific boundary conditions of each theory-the additional variables that will generate the incentive effect versus the dissonance effect-has proved unsuccessful, particularly with regard to producing the direct relationship (cf. Collins \& Hoyt, 1972; Schlenker, Note 1).

Both approaches acknowledge that monetary payment can take on somewhat different social meanings depending on the context in which it is offered. For example, Rosenberg (1965) contended that large payments are sometimes viewed as bribes. Typically, though, researchers have regarded these social meanings as artifacts that should be eliminated rather than as an integral part of the phenomenon of interest. Consequently, some of the implications of these meanings have not been adequately pursued, particularly as they reflect on the social identities of subjects who participate in forced compliance experiments. The concerns that different meanings of payment generate for subjects could in part determine how they respond, and hence affect whether an inverse or direct relationship is obtained.

\section{Self-Presentation and the Forced Compliance Paradigm}

It has been suggested that attitude change often represents an identity protecting or enhancing tactic used for self-presentational purposes (e.g., Alexander \& Knight, 1971; Schlenker, 1973, 1978, 1980; Schlenker \& Schlenker, 1975; Tedeschi, Schlenker, \& Bonoma, 1971). ${ }^{1}$ Self-presentation is the conscious or unconscious attempt to control selfrelevant images that are projected in real or imagined social interactions (Schlenker, 1980). Since people respond to others on the basis of the identities that those others create, everyone finds it to his or her advantage to control the self-images that are presented. Some such attempts are deliberate tactical gestures designed to create a desired impression, whereas others are well-ingrained habitual responses triggered by social cues.

The counterattitudinal advocacy paradigms typically employed by social psychologists induce subjects to lie, cheat, harm others, refrain from doing what they would prefer to do, or otherwise make themselves appear to be immoral, unattractive, incompetent, or irrational. In other words, most counterattitudinal advocacy paradigms place subjects in a predicament that could threaten their projected identities and associate them with numerous undesirable images." When confronting predicaments, people seem to employ self-presentational activities to remedy the situation and restore (as much as possible) their desired identities. Accounting tactics are a major type of remedial activity. Accounts are explanations or interpretations of a predicament-creating event that are designed to minimize the severity of the predicament.

The two major classes of accounts are excuses and justifications (Lyman \& Scott, 1970; Schlenker, 1980). Excuses are attempts to minimize one's responsibility for the predicament, and include such tactics as denying one did it, citing external coercive pressures (e.g., "He made me do it"), or citing internal coercive pressures (e.g., "I couldn't help it, I was . . . drunk, mentally ill, etc."). Justifications allow a person to admit responsibility but attempt to minimize the negative consequences of the action. For example, one might justify harming another person by noting why he or she deserved it or by explaining why the consequences were not really harmful. People who believe that marijuana is harmful but who are induced to persuade athers to smoke it (e.g., Nel, Helmreich, \& Aronson, 1969) might justify their actions by proclaiming that marijuana is not very harmful. By moderating their attitudes, they justify the action.

Following a predicament, accounting activities should be more likely to occur and be of

1 Social identity is a composite picture of an individual as a social being. Just as the self-concept can be defined as a theory about oneself (Epstein, 1973), so can identity be defined as a theory about a person that describes the way the individual is defined and regarded in interaction (see Schlenker, 1980).

2 Predicaments are situations in which events have undesirable implications for the images actors have claimed or desire to claim in front of real or imagined audiences, such as when one's actions are embarrassing, socially undesirable, antinormative, illegal, or disruptive (Schlenker, 1980) 
greater magnitude as both the undesirability of the predicament-creating event increases and as the actor appears to be more responsible for causing the event. The more negative the action appears to be and the greater the responsibility that can be attributed to the actor, the more imperative it is to eliminate, or at least minimize, the potential for guilt, disapproval, and punishment.

In the typical counterattitudinal advocacy paradigm, subjects are given high or low decision freedom about performing a persuasive speech that they expect will harm (mislead) or not harm (not mislead) another person. If no harm arises from the counterattitudinal speech, no accounting tactics are necessary. If it is obvious that subjects have no responsibility for the behavior (i.e., have low decision freedom), again no accounting is necessary - the subjects already have a visible, ready-made environmental excuse. However, when a person appears to be personally responsible for producing harm, accounting is necessary. Since the experimenter has already emphasized that the subjects have high decision freedom, the subjects cannot excuse their actions-the experimenter-audience would not accept it. The only accounting tactic available is to try to justify the behavior through attitude expressions. If subjects say that they do not strongly disagree with the contents of their persuasive speeches, then no harm has been done and they have accounted for their predicament. Subjects cannot be faulted for trying to persuade others to adopt a position the subjects do not find personally offensive. Attitude change toward the content of counterattitudinal actions can thus be a justification tactic employed when a person initially appears to be personally responsible for producing aversive consequences. Numerous studies have found that subjects must appear to be responsible for aversive consequences for attitude change to occur following counterattitudinal behavior (e.g., Calder et al., 1973; Collins \& Hoyt, 1972; Hoyt, Henley, \& Collins, 1972; Verhaeghe, 1976).

\section{Self-Presentation and Monetary Payment}

Although monetary payments can be interpreted in many different ways, including as rewards for achievement, in most situations that arouse a predicament they are perceived as: (a) environmental variables that affect levels of responsibility in a manner similar to a decision-freedom manipulation, or (b) variables that raise questions about possible illegitimate aspects of the action and the payee's moral values (e.g., the payment could be a bribe to perform a morally questionable task). Whether an inverse or direct relationship between payment magnitude and attitude change occurs should be partly determined by which of these two identity concerns is salient in the situation.

Self-presentation and the inverse relationship. Numerous theorists have hypothesized that monetary payment acts as an environmental variable giving people either high or low responsibility for their actions (e.g., Bem, 1972; Collins \& Hoyt, 1972; Kelley, 1967; Steiner, 1970). Under conditions in which monetary payment is seen simply as an environmental variable that affects personal responsibility, the effects of payments should be comparable to manipulating high or low choice for performing the behavior. That is, high decision freedom plus low monetary payment gives subjects high personal responsibility; if aversive consequences are also present, justification through attitude change occurs. If decision freedom is low or payment is high, an environmental excuse is provided for the action and no accounting is necessary irrespective of the consequences. These are precisely the conditions under which the inverse relationship has been consistently obtained (Calder et al., 1973; Collins \& Hoyt, 1972; Hoyt et al., 1972; Linder et al., 1967; Sherman, 1970).

Self-presentation and the direct relationship. A direct relationship should occur when people believe that payment represents an attempt to examine their moral turpitude. If cues lead people to believe that a payment is illegitimate (e.g., a bribe or an attempt to improperly discharge an obligation), then they should be concerned with not conveying the image of an immoral individual who will do anything for money. Take the case of subjects who accept $\$ 10$ to write a short essay on a topic they and most others oppose and, for whatever reason, want to convey the im- 
pression that they were not bribed. Rosenberg (1965) suggested that subjects would try to accomplish this goal by not changing their attitudes on the topic. Yet this tactic would only succeed if it was clear exactly where the subjects stood on the counterattitudinal issue prior to the behavior. If the experimenter knew they were vigorously opposed to the essay topic, any subsequent change in attitudes would probably be taken to mean that the payments had influenced or bribed them. However, in virtually all counterattitudinal behavior studies, subjects believe that their prior attitudes on a particular issue are unknown or only very generally known by the experimenter.

Given such prebehavioral attitude ambiguity, expressing no attitude change (i.e., taking an extreme negative position on the issue) after performing a counterattitudinal action demonstrates precisely what people hope to avoid. It indicates that the actor vehemently disagreed with the contents of the essay and therefore must have performed it to get the payment-he or she was bribed. Instead, the most effective accounting tactic would be to express a less negative, moderate attitude toward the issue. In this way, subjects show that their attitudes are not drastically inconsistent with the essay and therefore they were not bribed: They held the more moderate position prior to the performance and the payment had no effect on them. When moral concerns become salient in the situation, justifications are needed following large payments to demonstrate that the action was not harmful and not performed merely to receive money.

These hypotheses are similar in many respects to those contained in Kelman and Baron's $(1968,1974)$ functional approach to cognitive inconsistency. They argue that inconsistency does not produce a drive state in its own right; it is not a "master motive" for behavior. Instead, it is a signal to the individual indicating that his or her coping mechanisms are not functioning properly. In situations that involve a violation of an important moral precept, which they term "moral dissonance" situations, the signal produces a guilt reaction and efforts aimed at undoing the "reprehensible" act. They suggest that "in moral dissonance situations the greater the reward the greater the psychological discomfort. That is, the knowledge of having allowed oneself to be 'bought,' of having violated one's values for a price, may actually increase one's feelings of guilt" (p. 334). In contrast, "hedonic dissonance" situations are merely ones that are "boring, unpleasant, effortful, or nonsensical." Such situations are presumed to generate more short-lived discomforts and produce the typical dissonancetype relationship of more tension following smaller payments for performance of the tasks.

According to the Kelman and Baron analysis, situations that involve freely telling a harmful lie would seem to be categorized as producing moral dissonance. However, it is clear from past research that such situations often produce an inverse relationship between payment magnitude and attitude change instead of the direct relationship predicted. In contrast, we suggest that such a situation could involve either high or low moral concerns depending on the context in which the payment is introduced. If it is introduced in a context that increases subjects' concerns about moral evaluation relevant to bribery, a direct relationship should occur; but if it is introduced in a context that minimizes moral evaluation relevant to bribery, an inverse relationship should occur.

A variety of contextual factors should increase moral evaluation and focus people on the illegitimate aspects of payment. Payments might seem illegitimate for several reasons. It could become known that the payer was primarily interested in scrutinizing the person's moral values rather than simply having a task performed; the payment could be described as an inducement to elicit behaviors that are socially undesirable in nature; the payer might not really want the person to perform the task, but be under some external pressure to make the offer; or an undesirable task may have been performed as a personal favor to another individual, and the actor subsequently have received a large, unexpected payment from the other discharging the obligation. Of course, moral evaluation can also be decreased by a variety of factors. If, for example, the experimenter goes to 
great lengths to legitimize the payment, or subjects are distracted from moral concerns by some subterfuge (e.g., focusing them on the intellectual aspects of a complex task), then the money should not take on connotations of illegitimacy.

When moral evaluation is salient, payment magnitude may be directly, rather than inversely, related to responsibility. Kelley (1967, p. 218) proposed that "volition is high if the strength of illegitmate forces is high and you comply." Marvin E. Shaw (Note 2) found a curvilinear relationship between payment magnitude and responsibility: People were perceived as most responsible for their actions when payment was either insufficient or oversufficient (illegitimate). Thus for any particular situation, it can be suggested that a curvilinear, U-shaped relationship exists between payment magnitude and responsibility. When moral evaluation is increased in the situation, it should have the effect of shifting the curve. An inverse relationship between payment magnitude and attitude change obtained in the original situation should change into no relationship or even a direct relationship when moral evaluation is heightened. This is because a previously small payment that was seen as insufficient (generating high responsibility) and a previously large payment that was seen as sufficient (generating low responsibility) then become viewed as sufficient (low responsibility) and oversufficient (illegitimate, high responsibility), respectively.

Given a curvilinear relationship between payment magnitude and responsibility, the self-presentation hypotheses converge on a responsibility-for-consequences analysis of the forced compliance problem. Collins and Hoyt (1972) suggested that people must feel responsible for producing negative consequences before they will change their attitudes following counterattitudinal behavior. Their analysis was largely atheoretical in nature, but the self-presentational analysis arrives at a similar conclusion via a theoretical route. Given the nature of the forced compliance predicament, attitude change is most needed when people appear to be responsible for producing negative consequences-when they are paid either a small amount under conditions of low moral evaluation relevant to bribery or a large amount under conditions of high moral evaluation relevant to bribery.

A review of the studies that have found a direct relationship suggests that virtually all of them seemed to have established conditions that should have maximized concerns about immorality and illegitimacy. In general, two techniques can be used to affect perceptions of illegitimacy: (a) hold the task constant and vary payments across a wide range from very small (insufficient) to extremely large (illegitimate), or (b) hold payments at only two levels, small and large, and vary situational cues that increase moral evaluation.

The first technique was used by Gerard, Conolley, and Wilhelmy (1974). They found that when payments for performing a counterattitudinal action were varied from an insufficient to sufficient range, subjects changed their attitudes more the smaller the amount of payment, but when payments varied from a sufficient to an oversufficient range, subjects changed their attitudes more the greater the amount of payment.

The second technique, holding payment at two levels while varying situational factors that affect perceptions of illegitimacy, has also been used, often unintentionally. One important factor that produces differential perceptions of bribery is the amount of decision freedom provided by the experimenter. Kaufmann (1971) found that observers of a counterattitudinal behavior situation perceived a monetary payment to be more of a bribe when participants were given low rather than high freedom to refuse participation. This rather paradoxical result might make sense from a moralistic point of view. Since an experimenter cannot "force" a subject to do something against his or her will in a typical laboratory study, the failure to mention that the subject can decline participation may highlight the fact that the experimenter believes the payment is "buying" participation. When a high amount of decision freedom is given, the payment may retreat further into the background; the payment then seems to be only one of the many factors that could affect a decision to participate.

Consistent with this explanation, most (al- 
though not all) studies that have found the direct relationship have done so when subjects were given low decision freedom about performing the behavior (Calder et al., 1973; Gerard, 1967; Linder et al., 1967; Rosenberg, 1965; Sherman, 1970). For example, Calder et al. (1973) had subjects complete a boring task and then tell a confederate that the task was interesting. They found the direct relationship only when subjects were given low choice about telling the lie and the confederate was harmed by believing the lie. Thus it seems that once subjects are given low choice about agreeing to do something antinormative for payment, the remainder of the experiment must be relatively uneventful to wipe out the perception of bribery and moral evaluation.

The direct relationship can still be obtained when subjects are given high decision freedom, although it seems to take more significant events to heighten moral evaluation to the point at which it emerges. Janis and Gilmore (1965) gave subjects high choice and either $\$ 1$ or $\$ 20$ to write a brief counterattitudinal essay. They found that the $\$ 20$ subjects were suspicious of the inordinately large amount of money offered to them, and that they tended $(p<.10)$ to change their attitudes more than the $\$ 1$ subjects. The attitude change trend that accompanied the increased suspicions is consistent with the above prediction but is contrary to the effects of suspicion hypothesized by Rosenberg (1965).

Nuttin (1975, Experiment 9) had subjects write a counterattitudinal essay under moderate choice conditions and surreptiously offered some of them a highly illegitimate reward of exam "rescue" points. Compared to subjects who were not offered the blatant bribe, the ones who received points showed dramatic attitude change effects.

Finally, Elms and Janis (1965) paid subjects a small or large amount to write essays advocating the sending of American students to universities in the Soviet Union for their 4 years of college. It was explained that the American government was "skeptical" about the plan and reluctant to support it, although the Soviet government was enthusiastic about it. Subjects changed their attitudes in the direction of the essay only when they were paid a large amount by a "favorable sponsor" -an interviewer hired by the U.S. State Department. An "unfavorable sponsor"-an interviewer hired by the Soviet embassyproduced no change. Although these results are often interpreted as supporting incentive theory and disconfirming dissonance predictions, they are consistent with the selfpresentation position. In the favorable sponsor condition, subjects were being evaluated by someone who should have induced high moral evaluation: The interviewer was presented as an extension of the government's attitude that the plan was "suspect." Hence, with moral evaluation high, subjects in the large payment condition justified their actions to appear as if they did not do something they and the interviewer would regard as reprehensible solely to obtain the money. In the unfavorable sponsor condition, though, the interviewer was hardly in a position to create high moral evaluation: He both agreed with the position of the essay and was himself hired or bought by the Soviet embassy. Moral evaluation, at least vis-à-vis the immediate interviewer-audience, should be lower, although perhaps not to the point at which the inverse relationship emerges.

\section{Experiment 1}

Three experiments were conducted to directly examine the adequacy of the hypotheses regarding the meaning of monetary payment. In the first experiment, subjects agreed to be videotaped performing a counterattitudinal speech that would persuade an audience and received either a small or large payment. After they made the speech, the experimenter introduced information that emphasized morality (by stating that the relationship between moral values and behavior was being examined) or minimized moral concerns (by stating that the relationship between topic beliefs and behavior was being examined). According to the above hypotheses, an interaction of incentive magnitude and moral emphasis should be obtained under these conditions. An inverse relationship should occur between payment magnitude and attitude change when moral evaluation is minimized, 
whereas a direct relationship should occur when it is maximized.

\section{Method}

Subjects. Eighty introductory psychology students partially fulfilled a course requirement by participating in the study. Sixteen subjects (eight males and eight females) were included in each cell of the two ( $\$ 50$ vs. $\$ 2.50$ payment) by two (high vs. low moral evaluation) posttest-only factorial design with an offset control condition (attitude measurement only). An additional three subjects refused to participate, two complaining of "camera-shyness," and one refusing to make a speech against seat belt usage. Two experimenters, one female and one male, tested an equal number of subjects in all conditions, ${ }^{3}$

Procedure. Subjects were tested individually in a laboratory room that contained a table; chairs; a videotape camera, recorder, and monitor; and a large one-way mirror on one wall. The cover story was a modification of the instructions used by Riess and Schlenker (1977). Subjects were told that the study was investigating the relative efficacy of different patterns of persuasive messages arguing either for or against a specific issue-in this case, the use of seat belts in automotive vehicles. Videotaped messages of various types, prepared by college students, supposedly would be shown to groups of junior high school students to determine message effectiveness. Measures of subsequent attitudes toward seat belts and the actual use of seat belts were expected to demonstrate that the junior high school students would be quite persuaded by the messages. Thus an anti-seat-belt speech had foreseeable negative consequences for the audience. The use of college students as communicators was justified by explaining that the generalizability of the results would be enhanced through the use of a variety of communicators and messages.

Almost as an aside, the experimenter mentioned that some other researchers were developing a new technique for coding and analyzing live speeches. When they heard about the present study, they thought it would be a perfect opportunity to use the new rating scales. They had therefore requested and received the cooperation of the experimenter in allowing raters to observe the speeches and try out their scoring techniques. These raters would be watching the proceedings from behind the one-way mirror, where they could work without disturbing the participants. It was stressed that the observers were not part of the "opinion research study" for which subjects had signed up. No observers were actually present, but use of this cover story provided a justification for obtaining attitude measures from a person other than the experimenter and allowed for the introduction of the moral evaluation manipulation later.

The experimenter emphasized that the subjects could choose to write an essay arguing for or against the use of seat belts. However, to keep the procedure somewhat uniform, a predesignated sequence for completing the tapes supposedly had been prepared and was being followed as closely as possible. The experimenter stated that it would be helpful if the subjects would select the specch that was next in the sequence, which was "Seat belts can be dangerous and should not be worn by operators and passengers in automotive vehicles," but that the choice was theirs. The experimenter also mentioned that the project was being funded by a grant, so they could be paid $\$ .50(\$ 2.50)$ for their participation. This payment was in addition to the normal experimental credit slip that they would receive and would give to their instructor to indicate that they had participated. After the choice instructions and payment were described, subjects were asked if they would agree to participate using the anti-seat-belt topic, and to indicate their agreement by signing a consent slip.

A short list of sample arguments against the use of seat belts was given to help stimulate thought, and subjects werc allowed 15 minutes to prepare and practice their presentation before delivering it into a videotape camera operated by the experimenter. The speeches were to be "about a page or so in length, so that it will come out to be about 2 minutes or under on the videotape." They were asked to identify themselves on the tape as university students but not to give their names. After completing the tape, subjects were paid and given a credit slip; while doing so, the experimenter reinforced the negative consequences of the speech by stating that it should be quite effective for persuasive purposes.

The experimenter then stated that the study was completed. However, the observers in the next room supposedly had asked if subjects could spare a few minutes to assist them in their work by completing a brief questionnaire. The moral evaluation manipulation was introduced at this point. In the high moral evaluation condition, the experimenter explained that the observers were interested in developing a reliable measure that related behaviors to moral values. The experimenter stated that

They think, and you would probably agree, that the way people act is usually related to their moral and ethical values. So maybe by looking at the way a person talks or acts in a certain situation, an observer can tell the way that person feels. Simply, to what degree do a person's behaviors correspond to their feelings in situations like this, and to what degree can observers of

${ }^{3}$ Sex of subjects and experimenter was included in the analyses of all three experiments. No significant effects that qualified the reported results were revealed on attitude change, and no consistent patterns were obtained on the other dependent variables. Consequently, these factors will not be mentioned further. 
this situation determine what these moral and ethical values are?

In the low moral evaluation condition, subjects were told that the observers were interested in developing a reliable measure that related behaviors to an individual's own attitude on a topic. The experimenter stated that

They think, and you would probably agree, that the way people act is usually related to their opinions and beliefs. So maybe by looking at the way a person talks or acts in a certain situation, an observer can tell the way that person feels toward an issue. Simply, to what degree do a person's behaviors correspond to their attitudes in situations like this, and to what degree can observers of this situation determine how consistently a person is behaving with his own beliefs on a topic?

The manipulation of moral evaluation was introduced after subjects had completed the speech so that it would not affect either their decision to make the speech or their actual speech behaviors.

In all experimental conditions, the experimenter then stated that the speech raters had developed a questionnaire to get the type of information they needed. All subjects agreed to complete the questionnaire. The experimenter left the room, supposedly to get a copy from the observer, and returned with it and an envelope. Subjects were told to seal the questionnaire in the envelope when finished and that it would be delivered to the speech raters. The experimenter left the room while the subjects completed the questionnaire.

The questionnaire included (a) 24 7-point bipolar attribute scales to be used in responding to the statement "The use of seat belts is - (examples of endpoints were good-bad, helpful-harmful, a waste of time-time well spent); (b) the item "Seat belts can be dangerous and should not be worn by operators and passengers in automotive vehicles," to which subjects were to express the extent of their agreement or disagreement on a 13point scale; (c) 7-point bipolar attribute scales to be used to rate the quality of the speech ( 15 items, c.g., logical-illogical, interesting-uninteresting); and (d) five items on 18-point scales that asked subjects to rate the amount of choice they had had in agreeing to do the speech, the amount of responsibility they had had in agreeing to do the speech, the amount of responsibility they had for the contents of the speech and for any persuasive consequences of the speech, the degree of persuasiveness of the speech, and the quality of their speech performance. When subjects had completed the questionnaire and placed it in the envelope, the experimenter returned and handed them a page containing manipulation checks and other ancillary measures (on 18-point scales).

The 16 subjects in the control condition did not prepare or deliver a speech. They reported to the lab individually and completed the measures of at- titudes toward seat belts (parts a and b above) as part of an "opinion survey."

The self-presentation approach predicts that people will try to escape from predicaments by redefining the situation to make it appear to be socially acceptable. Consequently, "manipulation checks" that ask subjects who are placed in a predicament about possible bribery, moral evaluation, responsibility, and illegitimacy might not be expected to reveal subjects' actual feelings. For example, subjects paid $\$ 2.50$ under high moral evaluation conditions should want to avoid bringing further attention to such evaluation and should not want to admit being bribed, morally evaluated, or guilt-ridden about their plight. Indeed, Calder et al. (1973) found that subjects in conditions that displayed the greatest attitude change (i.e., low incentive/high choice/high consequences and high incentive/low choice/high consequences) also reported the fewest misgivings about their behavior. To obtain information about how the manipulations were perceived by subjects who were not placed in the counterattitudinal-behavior predicament, the experimenter's script was used to write a detailed scenario describing the exact procedure. The scenario described the experience of a typical subject, named Pat, who signed up for the study, reported to the laboratory, was told exactly what the subjects were told, and then performed the speech. Four different booklets were constructed that corresponded to the cells of the 2 (Payment Magnitude) $\times 2$ (Moral Evaluation) factorial design. Except for the variations of the independent variables, the booklets were identical and faithfully duplicated the script. The booklets were randomly distributed to 27 male and 16 female undergraduates as part of a "person perception" study; each subject read one scenario describing one of the four cells. After reading the scenario, these "observer" subjects were asked to record their reactions on 15point scales with labeled endpoints. The items assessed the subjects' own moral reactions to Pat's behavior, their perceptions of how Pat felt about the behavior, their perceptions of how the observers behind the one-way mirror felt about Pat's behavior, and ratings of the monetary payment.

\section{Results}

Payment, legitimacy, and moral concerns. Subjects perceived the money to be worth more to them in the $\$ 2.50$ than in the $\$ .50$ condition, $F(1,56)=4.96, p<.03(M \mathrm{~s}=$ 6.4 and 3.5 , respectively). In addition, the responses of the uninvolved observers indicated that the moral evaluation manipulation was perceived appropriately. They believed that greater stress was placed on the consistency between moral values and behaviors in the high moral evaluation condition, 
whereas greater stress was placed on the consistency between topic beliefs and behaviors in the low moral evaluation condition, $F(1$, $35)=6.64, p<.01(M \mathrm{~s}=3.8$ and -2.0 , respectively).

To test the hypothesis that the magnitude of payment is directly related to moral condemnation when moral evaluation is high, the observers were asked to respond to three items that assessed moral and ethical evaluations. Payment Magnitude $\times$ Moral Evaluation interactions were obtained on each of the following questions: "How ethically acceptable do you think Pat's actions were?", $F(1$, $35)=3.85, p<.06$; "How do you think Pat felt about his/her actions (considered them moral-considered them immoral)?", $F(1,35)=4.42, p<.05$; and "How do you think the observers (speech raters) reacted to Pat's behavior (considered it moral-considered it immoral)?", $F(1,35)=4.71, p<$ .04. As shown in Table 1, Pat's behavior was perceived as least moral when paid $\$ 2.50$ in the high moral evaluation condition, providing strong support for the underlying assumptions of the study.

Observer-subjects were also asked to rate how earned-unearned, deserved-undeserved, and honest-dishonest (on 7-point scales) was the money paid to Pat. A Payment Magnitude $\times$ Moral Evaluation interaction was obtained on the sum of these items, $F(1,35)$ $=5.77, p<.02$. Observers viewed the money least positively, $p<.05$, when Pat was paid $\$ 2.50$ in the high moral evaluation condition $(M=12.2)$. The other conditions did not differ amongst themselves (means for the $\$ .50 /$ high evaluation, $\$ .50 /$ low evaluation, and $\$ 2.50 /$ low evaluation conditions were $15.4,14.1$, and 15.3, respectively). Once again, the money evoked less positive reactions related to illegitimacy when payment was high and moral evaluation was salient.

Attitudes toward seat belts. The predicted Payment Magnitude $\times$ Moral Evaluation interaction was obtained on subjects' agreement with the item "Seat belts can be dangerous and should not be worn by operators and passengers in automotive vehicles," $F(1$, 56) $=5.45, p<.02$. As shown in Table 2, a direct relationship between payment magnitude and attitude change was suggested in the high moral evaluation condition, whereas an inverse relationship between these variables was obtained in the low moral evaluation condition. Planned comparisons with the control condition revealed significant attitude change in the $\$ .50 /$ low evaluation condition, $t(75)=2.05, p<.05$; however, the $\$ 2.50 /$ high evaluation condition failed to differ significantly from the control condition, $t(75)$ $=1.61, p<.12$ (all tests were two-tailed). The inverse relationship in the low moral evaluation condition was significant, $t(75)=$ $2.05, p<.05$, whereas the direct relationship failed to reach significance, $t(75)=1.39, p$ $<.20$.

An identical pattern was revealed on affective ratings of "the use of seat belts" derived from the semantic differential scales. Factor analysis was performed on the 24 bipolar adjective ratings to extract a single factor representative of evaluative, affective feelings toward seat belts; most theorists equate only the evaluative dimension of the semantic differential with the concept of attitudes (Fishbein \& Ajzen, 1975). ${ }^{4}$ The factor analysis was done using principle axes and orthogonal varimax rotations and revealed one major factor that accounted for $50.7 \%$ of the total variance (eigenvalue $=12.17$ ); no other factor accounted for more than an additional $5 \%$ of the total variance. Sixteen of the 24 items loaded heavily on the evaluative factor, with the highest loadings derived from wisefoolish (.92), good-bad (.89), beneficialdetrimental (.82), and safe-dangerous (.76). Analysis of variance performed on the factor scores revealed a significant Payment Magnitude $\times$ Moral Evaluation interaction, $F(1$, $56)=6.87, p<.05$. As shown in Table 2,

\footnotetext{
* The factor analysis was performed using the combined data from Experiments 1 and 2, both of which used the same scales to obtain ratings of seat belts, and included both control groups. This was necessary to allow for comparisons across groups and studies and to increase the number of subjects included to produce greater stability of the analysis. Separate factor analyses were done within each study and provided support for the compatibility of the two data sets. These analyses were done using the pooled within-cell correlation matrix, thereby correcting for possible treatment effects within each experiment.
} 
Table 1

Payment Magnitude $\times$ Moral Evaluation

Interactions on Observer's Moral Evaluations

\begin{tabular}{|c|c|c|c|c|}
\hline \multirow{3}{*}{$\begin{array}{c}\text { Dependent } \\
\text { variable }\end{array}$} & \multicolumn{4}{|c|}{ Condition } \\
\hline & \multicolumn{2}{|c|}{$\begin{array}{l}\text { High moral } \\
\text { cvaluation }\end{array}$} & \multicolumn{2}{|c|}{$\begin{array}{l}\text { Low moral } \\
\text { evaluation }\end{array}$} \\
\hline & $\$ .50$ & $\$ 2.50$ & $\$ .50$ & $\$ 2.50$ \\
\hline $\begin{array}{l}\text { Observer's } \\
\text { evaluation } \\
\text { Pat's }\end{array}$ & $13.2 \mathfrak{a}$ & $9.4_{b}$ & $12.3_{\mathrm{a}, \mathrm{b}}$ & $12.1_{\mathrm{a}, \mathrm{b}}$ \\
\hline $\begin{array}{l}\text { evaluation } \\
\text { Rater's }\end{array}$ & $12.6_{\mathrm{a}, \mathrm{b}}$ & $10.2_{b}$ & $11.9_{\mathrm{a}, \mathrm{b}}$ & $13.3_{\mathrm{n}}$ \\
\hline cvaluation & $12.0_{\mathfrak{a}}$ & $8.9_{\mathrm{b}}$ & $10.3_{\mathrm{a}, \mathrm{b}}$ & $10.1_{a, b}$ \\
\hline
\end{tabular}

Note. Higher means indicate that the behavior was perceived as more moral. Means without a common subscript differ by at least $p<.05$ using Iuncan's multiple-range test.

the direct relationship was again suggested in the high moral evaluation condition, and the inverse relationship was evidenced in the low moral evaluation condition. The inverse relationship was significant, $t(75)=2.91, p<$ .05 , but the direct relationship was not, $p<$ .20. Also, comparisons with the control group revealed significant attitude change only in the $\$ .50 /$ low moral evaluation condition, $t(75)=2.22, p<.05$.

Subjects' perceptions. Although the direct relationship between payment magnitude and attitude change was suggested on both attitude measures in the high moral evaluation condition, it failed to reach conventional levels of statistical significance. One possible reason for the failure could be that the subjects attempted to redefine the larger payment as being relatively legitimate, thereby reducing their predicament and the need for justificatory attitude change. Analyses of several measures support this interpretation. Two items asked subjects to rate why the money was given to them ("to induce you to make the speech" and "to encourage you to do a good job" on the speech, each followed by an 18-point scale). No effects were found on the inducement item, as subjects responded on the "not the reason" side of the scale's midpoint $(M=7.1)$. However, a main effect of payment magnitude revealed that subjects more often said that the money was to get them to do a good job in the $\$ 2.50$ than in the $\$ .50$ condition, $F(1,56)=4.15, p<$ $.04(M \mathrm{~s}=9.3$ and 6.2 , respectively). Thus subjects avoided describing the payment as an inducement and preferred, when payment was large, to label it as an incentive for superior performance.

Similarly, when responding to two items that assessed the degree to which they agreed to do the speech to accommodate the experimenter and to get the money, subjects emphasized that their agreement was almost totally to accommodate the experimenter ( $M$ $=15.7$, no effects were obtained). However, main effects of moral evaluation, $F(1,56)=$ $6.00, p<.02$, and payment magnitude, $F(1$, $56)=6.01, p<.02$, showed that subjects said they agreed less for the money in the high than low moral evaluation condition $(M \mathrm{~s}=1.6$ and 3.0 , respectively $)$, and less for the money in the $\$ .50$ than in the $\$ 2.50$ condition ( $M_{\mathrm{S}}=1.6$ and 2.9 , respectively). These means fall close to the "not at all for the money" side of the scale, but indicate that when moral concerns are high, the importance of the money as a decision-affecting factor is further denied. In addition, a main effect of moral evaluation showed that when asked how they interpreted the money, subjects said it was less of a bribe in the high than low moral evaluation condition, $F(1$, $56)=11.61, p<.01(M \mathrm{~s}=3.8$ and 8.0 , respectively). Finally, no effects were obtained when subjects were asked how much stress was placed on moral evaluation $(M=9.7)$.

In sum, unlike the uninvolved observers, who disparaged the $\$ 2.50$ payment when moral evaluation was salient, the experimental subjects did not admit high moral evaluation, stated that they agreed to do the speech almost totally to accommodate the experimenter, and stated that the large payment was primarily to get them to do a good job on the speech rather than to induce them to make the speech. Subjects in the high moral evaluation condition also denied that they agreed to perform the speech in order to get the money and rated the money as less of a bribe. The pronounced differences between the patterns for the uninvolved observers and the experimental subjects suggests that the high moral evaluation condition subjects were 
Table 2

Attitudes Toward Seat Belts: Experiment 1

\begin{tabular}{lccc}
\hline & \multicolumn{2}{c}{ Condition } \\
\cline { 2 - 3 } Item and condition & $\begin{array}{c}\text { High moral } \\
\text { evaluation }\end{array}$ & $\begin{array}{c}\text { Low moral } \\
\text { evaluation }\end{array}$ & Control \\
\hline Agree-disagree item & & & 3.4 \\
$\$ .50$ & 3.6 & 5.8 & \\
$\$ 2.50$ & 5.2 & 3.5 & \\
Semantic differential items & & & -.05 \\
$\$ .50$ & -.06 & .53 & \\
$\$ 2.50$ & .34 & -.43 & \\
\hline
\end{tabular}

Note. Higher positive scores indicate greater opposition to seat belt usage, or less favorable evaluations of seat belts (i.e., more attitude change).

attempting to account for the predicament by emphasizing situational factors that would make the payment appear to be more legitimate.

Perceptions of speech quality, choice, and responsibility. No independent variable effects were obtained on subjects' ratings of the quality of their performance or the quality, persuasiveness, or consequences of the speeches (the consequences were rated as being slightly on the "detrimental" as opposed to the "beneficial" side of the scale's neutral point, $M=9.2$ ). They also stated that they had "moderate choice" in deciding on which side of the topic to write an essay ( $M=$ 8.6), "some responsibility" for any persuasive consequences of the speech $(M=7.2)$, and "moderate responsibility" for the content of their speech $(M=9.1)$.

\section{Discussion}

When moral evaluation was deemphasized, a significant inverse relationship was obtained between payment magnitude and attitude change on both attitude measures, and significant attitude change compared to the control condition occurred in the $\$ .50 /$ low moral evaluation condition. By moderating their attitudes, these subjects apparently justified their behaviors. The inverse relationship is consistent with the predictions made by the self-presentation approach, as well as those made by dissonance theory and self-perception theory. All assume that the subjects' responsibility for the aversive consequences (or, for self-perception theory, the apparent internal origin of the action) was greater in the small rather than the large payment condition. The failure to find differences in perceived responsibility for the action does not seem critical to the validity of any of the theories. Either the term "responsibility" may carry different connotations for theorists than for subjects, producing an insensitive measure, or as a consequence of justifying the behavior or reducing dissonance, subjects may not object to admitting moderate responsibility for the action under both payment magnitude conditions.

When moral concerns were accentuated, however, the inverse relationship disappeared and a slight but nonsignificant direct relationship between payment magnitude and attitude change occurred. The uninvolved observers stated that moral evaluation was greater in this condition and condemned the behavior of subjects paid $\$ 2.50$. The apparent illegitimacy of the larger payment should have produced attitude change designed to show that the action was legitimate and not influenced by monetary concerns. Indeed, subjects in the high moral evaluation condition did show such an attitude change trend, and also attempted to account for the predicament by emphasizing factors that made the payment appear to be more legitimate. These direct legitimizing tactics minimized the need for justificatory attitude change. 


\section{Experiment 2}

The major limitation of the data from Experiment 1 was the failure to obtain a stronger direct relationship between payment magnitude and attitude change in the high moral evaluation condition. Rather than demonstrating significant attitude change that would justify and legitimize the situation, these subjects apparently legitimized the payment directly through their interpretations of why payment was offered and what effects it had on them. If such tactics could be blocked, then the direct relationship should emerge.

Experiment 2 allowed a means of blocking these alternative accounting tactics by explicitly defining the reason why the money was being paid. Prior to agreeing to make the counterattitudinal speech against seat belts, subjects were told that the money was being offered either as an explicit inducement to get them to agree to make the speech (agreement condition) or as an incentive to get them to do a good job on the speech (performance condition).

The agreement condition should block attempts by subjects to redefine the large payment as a legitimate incentive and should heighten moral concerns. Prior counterattitudinal behavior studies have typically introduced payments in an ambiguous way, such that they could be perceived as inducements, incentives, or both. The present focus on only the inducement aspect should increase possible illegitimacy and hence moral evaluation. Consequently, a direct relationship should be obtained between payment magnitude and attitude change in the agreement condition. Subjects in the performance condition, however, do not have to do anything to legitimize the payment, because the experimenter has legitimized it for them-it is not to get them to agree to do the speech, only to get them to do a high caliber performance that will benefit the research project. Additionally, initial responsibility might be roughly equated in the performance condition irrespective of payment magnitude by virtue of the fact that payment is presumably not offered to affect decisions to perform the task. If payment is supposedly unrelated to agreement, it should be unrelated to responsibility; consequently, magnitude should be unrelated to justificatory attitude change.

\section{Method}

Subjects. Eighty introductory psychology students partially fulfilled a course requirement through participation. Sixteen subjects (eight males and eight females) were included in each cell of the 2 (Payment Magnitude) $\times 2$ (Contingency) posttest-only factorial design with an offset control condition (attitude measurement only). Five additional subjects refused to make a speech against seat belts, with attrition distributed throughout the cells. Four experimenters, two males and two females, tested equal numbers of subjects in all conditions.

Procedure. The procedure was identical to that used in Experiment 1, with two exceptions: The reason for the monetary payment was explicitly manipulated, and the experimenter did not mention the topic under study by the speech raters prior to distribution of the questionnaires. As in Experiment 1, subjects were asked to make a potentially harmful anti-seat-belt speech under conditions of high choice for either $\$ .50$ or $\$ 2.50$. Subjects in the agreement condition were told, after the experimenter had noted that money was available, that the money was "intended to provide you with an extra reason for going ahead and agreeing to make the speech." Subjects in the performance condition were told that the money was "intended to provide you with an extra reason for doing a good job on the speech. We want you to make your arguments, examples, and presentation as persuasive as possible, so we decided that perhaps people would do a better job if we paid them $\$ .50(\$ 2.50)$ to write the essay and deliver the speech for us." These statements were reemphasized after the subjects had completed the videotapes. As the experimenter thanked subjects for their participation, they were handed their class credit slips and the appropriate amount of money and told that the money was either for "agreeing to make the speech for us" or "for doing the most persuasive and forceful speech possible." All subjects were then told, "Good job. Your essay should be quite persuasive," thus reemphasizing the negative consequences.

As in Experiment 1, the experimenter noted that the speech raters were interested in obtaining "background information about the communicators they observe," but no mention was made of the express purpose of the information. The questionnaire was similar to that used in Experiment 1, with the addition of appropriate manipulation checks and the deletion of irrelevant items.

As in Experiment 1, uninvolved observers (20 males and 26 females) were given booklets containing a scenario written by using the experimenter's script and including instructions from only one of the four key cells in the design. 


\section{Results}

Payment, legitimacy, and contingencies. Once again, subjects perceived the money to be worth more to them in the $\$ 2.50$ than $\$ .50$ condition, $F(1,56)=9.51, p<.01(M \mathrm{~s}$ $=9.1$ and 4.9 , respectively).

Before any attitude change displayed by subjects can be interpreted, it is necessary to determine if the experimental subjects appropriately perceived the contingencies and if the contingencies affected uninvolved observers' evaluations of the morality of the situation. The experimental subjects were asked to rate why the money was given to them on two scales-"to induce you to make the speech" and "to encourage you to do a good job" (18-point scales with endpoints labeled "definitely not the reason" and "definitely the reason"). A main effect of contingency was obtained on the good job item, $F(1,56)=$ $11.35, p<.001$, with subjects in the performance condition stating that the money was to encourage them to do a good job, and subjects in the agreement condition responding on the "not the reason" side of the scale's midpoint ( $M \mathrm{~s}=13.1$ and 8.4, respectively). Thus subjects in the agreement condition could not legitimize the payment by emphasizing the performance aspects of the money. The contingency manipulation had no effects on the "inducement" item, as subjects in both conditions responded on the "not the reason" side of the scale $(M=7.8)$. As might be expected, subjects in the agreement contingency condition did not want to label the payment as an "inducement" (bribe), even though they did have to admit that the payment was not offered to obtain a good performance (which presumably would be the only other reason that payment would be offered). Considering both items, the manipulation appears to have been successful.

The contingency manipulation also affected the observers' ethical reactions. A Payment Magnitude $\times$ Contingency interaction, $F(1$, $38)=4.12, p<.05$, was obtained on ratings of "How ethically acceptable do you think Pat's actions were?" When paid \$2.50, Pat was evaluated as less moral in the agreement condition than in the performance condition, $p<.05$ ( $M \mathrm{~s}=9.1$ and 11.4 , respectively).
The means for the $\$ .50$ conditions were intermediate $(M \mathrm{~s}=10.3$ and 9.4 for the agreement and performance conditions, respectively). A comparable, although less pronounced, interaction was obtained on the item "How do you think Pat felt about his/ her action?", $F(1,38)=2.90, p<.10$, although no effect was obtained on the question, "How do you think the observers (speech raters) reacted to Pat's behavior?"

Attitudes toward seat belts. Analysis of variance performed on the factor scores from the evaluative factor of the semantic differential ratings of seat belts revealed a Payment Magnitude $\times$ Contingency interaction, $F(1$, $56)=7.65, p<.01$. As shown in Table 3 , a significant direct relationship was obtained between payment magnitude and attitude change in the agreement condition, $t(75)=$ $4.11, p<.01$, whereas no effect was obtained in the performance condition. Subjects in the $\$ 2.50$ /agreement condition were the only ones to show significant attitude change as compared to the control condition, $t(75)=2.95$, $p<.01$. Agreement with the item "Seat belts can be dangerous and should not be worn by operators and passengers in automotive vehicles" revealed an identical interaction, $F(1$, $56)=3.27, p<.07$. Planned comparisons performed on the latter item, means for which are presented in Table 3 , revealed a significant direct relationship between payment magnitude and attitude change in the agreement condition, $t(75)=3.08, p<.02$; again, the $\$ 2.50$ /agreement condition was the only one to differ significantly from the control condition, $t(75)=2.90, p<.05$. On both dependent measures, subjects paid $\$ 2.50$ were significantly more negative toward seat belts when agreement rather than performance was stressed, $p \mathrm{~s}<.05$.

Subjects' perceptions. No effects of payment magnitude or contingency were obtained on ratings of choice in deciding on which side of the topic to make the speech $(M=7.4)$ and in deciding responsibility for the content ( $M=9.0$ ) or consequences ( $M$ $=7.4$ ) of the speech. However, subjects paid $\$ .50$ reported that the consequences of their speeches were slightly more harmful than subjects paid $\$ 2.50 \mathrm{did}, F(1,56)=5.83, p$ $<.02(M \mathrm{~s}=8.2$ and 10.1 , respectively $)$. 
Table 3

Attitudes Toward Seat Belts: Experiment 2

\begin{tabular}{cccc}
\hline & \multicolumn{2}{c}{ Condition } & \\
Item and condition & $\begin{array}{c}\text { Agreement } \begin{array}{c}\text { Performance } \\
\text { contingency } \\
\text { contingency }\end{array} \\
\text { Agree-disagree item }\end{array}$ & & Control \\
$\$ .50$ & 3.4 & 4.0 & 3.6 \\
$\$ 2.50$ & 6.6 & 4.4 & \\
Semantic differential items & & & \\
$\$ .50$ & -.49 & .15 & -.23 \\
$\$ 2.50$ & .45 & -.21 & \\
\hline
\end{tabular}

Note. Higher positive scores indicate greater opposition seat belt usage, or less favorable evaluations of seat belts (i.e., more attitude change).

Ratings of the quality of the speech performances revealed a Payment Magnitude $\times$ Contingency interaction, $F(1,56)=4.80, p$ $<.03$. When paid $\$ 2.50$, subjects said they did a better job in the performance condition than in the agreement condition, $p<.05(M \mathrm{~s}$ $=11.1$ and 7.6 , respectively), with the $\$ .50$ conditions being intermediate $(M \mathrm{~s}=9.7$ and 9.8 , respectively). No effects were obtained on an item asking how persuasive the speech was or on the average rating of the speech on the semantic differential scales.

\section{Discussion}

The results of Experiment 2 support the prediction of a direct relationship between payment magnitude and attitude change when moral evaluation is salient and payments cannot be legitimized by being interpreted as incentives for superior performance. The uninvolved observers were least favorable toward a person paid $\$ 2.50$ in the agreement condition; thus the situation effectively evoked moral concerns related to illegitimate payment, and legitimizing payment as a means of reducing the dilemma was blocked. Accordingly, the $\$ 2.50$ /agreement condition subjects changed their attitudes toward seat belts, demonstrating that they did not perform the task solely because of the payment. By recognizing the dangerous aspects of seat belts, they could be seen as acting in good conscience when they made the speech.

When payment was legitimized by making it appear to be an incentive for a quality per- formance rather than for agreement, no attitude change occurred. With subjects' attentions directed away from both moral concerns and the role of payment in getting them to agree to make the speech, no justification was apparently needed.

\section{Experiment 3}

In the first two experiments, moral evaluation was increased by informing subjects that either their moral values were under scrutiny or the payment for agreeing to perform the potentially harmful act was to be viewed solely as an inducement. To further reduce alternative interpretations of the effects of these manipulations, an even more direct means of raising moral evaluation was employed in Experiment 3. Some of the subjects were accused by the observers of having been bribed by the payment. Such an accusation should leave little doubt in the minds of the subjects about how their actions are being interpreted by an audience. In contrast, other subjects received a note from the observers indicating that the latter thought the payment was legitimate. If a direct relationship is again obtained between payment magnitude and attitude change in the bribe condition, it would provide even stronger support for the hypothesized effects of moral evaluation.

If attitude change in a forced compliance setting is a self-presentational tactic used when subjects confront a predicament, then the degree to which actors are concerned about the impression they are making on a 
particular audience should affect the amount of attitude change that occurs. To manipulate self-presentational concern, half of the actors were led to believe that the attitude questionnaires were being collected for the observers who had just commented on the payment (high self-presentational concern). The remaining actors were led to believe that the questionnaire was part of a psychology department survey to assess subjects' reactions to studies performed under its auspices (low self-presentational concern). To further dissociate the latter questionnaire from the experimenter and observer audiences, these subjects completed it on another floor of the building and were told that neither the experimenter nor the observers would see their responses. It was hypothesized that the interaction between payment magnitude and moral evaluation would be more pronounced in the high than in the low self-presentational concern condition. Further consideration of the effects of this manipulation as it bears on "genuine" attitude change will be reserved for the discussion.

Finally, subjects participated in pairs. One subject was assigned to perform the counterattitudinal task while the other unobtrusively observed the former's actions from behind a one-way mirror. Headphones permitted the observer to hear everything that transpired in the adjacent room. The use of actor-observer pairs allowed examination of possible differences in perceptions as well as examination of the degree to which the observers could correctly predict the actors' attitudes (cf. Bem, 1972).

\section{Method}

Subjects. Two hundred twenty-four introductory psychology students (seven males and seven females per cell) served in the 2 (Actor or Observer) $\times 2$ ( $\$ .50$ or $\$ 2.50$ Payment) $\times 2$ (Bribe or Legitimate Comment) $\times 2$ (Low or High Self-Presentational Concern) posttest-only factorial design. An additional 14 subjects ( 7 males and 7 females) were tested in the offset control condition, where they responded to the attitude items as part of an "opinion survey." Subjects were tested by one of two male or two female experimenters.

Procedure. The procedure closely followed those of the first two experiments with the following exceptions. Two same-sexed subjects reported indi- vidually to different waiting rooms, where they were greeted by the experimenter and led to adjoining laboratory rooms that were separated by a one-way mirror. The observer was seated at a table behind the mirror, provided with headphones that were connected to a microphone in the actor's room, and given a page of printed instructions. The instructions explained that he or she would be observing another subject participating in a study of persuasive speech making. They continued:

We are interested in examining how outside observers (like yourself) perceive the situation and the other subject's behavior. You will observe the other person through the one-way mirror and complete a questionnaire at the end of the study asking for your perceptions ... of the subject, his or her speech, the experimenter, and the experiment in general.

It was explained that to protect the observer's anonymity, the other subject would not know that he or she was watching, although the actor would know that other observers from the speach department were watching from behind a second one-way mirror in another adjacent room (once agair, no observers from the speech department were actually present). The instructions then reiterated the importance of paying close attention to the proceedings.

The actor was seated in the main laboratory room and given general tape-recorded instructions comparable to those of the prior studies. After noting the actor's choice in deciding to make the anti-seatbelt speech (but prior to the subject's agreement), the experimenter said, "I also need to mention that this project is being funded by a grant, and if you agree to do the speech we can pay you $\$ .50(\$ 2.50)$ in addition to the regular 1-hour credit that you will receive for your participation." Thus the payment was introduced in a way that implied an agreement contingency, but did not make it explicit as had been done in Experiment 2 .

After delivering the speech into the videocamera, the actor was paid and informed that the study was over. The experimenter then remarked in an offhand manner, "The observers from the speech department have rated your speech, which was the point of their watching, and since most people really wonder what the observers thought, I usually go get a copy of their rating form for them." He or she then left to get the form.

The form contained two general categories for ratings of the content of the speech and the presentation of the speech; each category was followed by five rating dimensions (e.g., organization, logic of arguments, persuasiveness, voice clarity, use of gestures). These were filled out to indicate that the speech and presentation had been evaluated as slightly above average, with the highest rating given for persuasiveness (thus reinforcing the belief that the speech would be effective in persuading the junior high school students). In addition, the bot- 
tom of the form contained a space for "Notes and Comments," and included a handwritten statement that introduced the bribery manipulation. The statement read: "Subject received payment for agreeing to participate-," and continued with either "Bribe?!?" (bribe condition) or "legitimate compensation; good idea to pay subjects" (legitimate condition). The experimenter gave one copy of the form to the observer, reiterating that the ratings were those of the speech observers, and then returned to give another copy to the actor.

After giving the subjects time to scrutinize the form, the self-presentational concern manipulation was introduced. In the high self-presentational concern condition, the actor was told that the speech raters were interested in his or her own perceptions of the speech, which would presumably assist them in refining their techniques. The actor was given a questionnaire, supposedly devised by the speech raters, asked if he or she would assist them by completing it, and told to seal the questionnaire in an envelope when finished so that it could be delivered to the raters. In the low self-presentational concern condition, the actor was told that the psychology department was interested in obtaining subjects' opinions about certain randomly selected studies as part of a process of evaluating studies conducted under its auspices. The actor was given directions to the main psychology office, which was on a different floor, and told that the questionnaire he or she would complete would not be shown to the experimenter or the speech raters. On arriving in the main office, the actor was greeted by a confederate who posed as a secretary-receptionist, was asked what study he or she had just participated in, and was given a questionnaire that was supposedly tailored for that study. After completing the questionnaire, the actor was asked to return to the laboratory room, where he or she was fully debriefed.

The questionnaire was similar to those used in the first two experiments with the addition of appropriate manipulation checks and other items (unless otherwise noted, ratings were on 18-point scales). The observer always completed the questionnaire in the original observation room. The items on the observer's questionnaire were phrased to parallel those on the actor's.

\section{Results}

Manipulation checks. Responses to the item, "How much was the money paid to you (the other subject) worth to you (him/her)?" revealed main effects of payment magnitude, $F(1,208)=37.21, p<.001$, and actorobserver role, $F(1,208)=6.59, p<.03$. Both actors and observers acknowledged that the $\$ 2.50$ payment was more valuable than the $\$ .50$ payment, $p \mathrm{~s}<.01$, but observers believed that the $\$ 2.50$ was even more valuable to the actors than the actors said it was, $p<.001$. Means for the actors and observers, respectively, were: small payment -3.7 and 3.8; large payment-5.9 and 8.9. The actors' relative denigration of the worth of the large payment may have represented an effort to counteract the appearance that they had performed the behavior to obtain a valuable reward.

The item, "How do you think the ... speech raters reacted to your (the other subject's) behavior?" (scale end points were labeled "considered it moral" and "considered it immoral") revealed a main effect of bribery emphasis, $F(1,208)=11.39, p<$ .001 , and a Role $\times$ Bribery Emphasis interaction, $F(1,208)=4.90, p<.03$. The main effect revealed that the manipulation was successful overall, with subjects stating that the behavior was less moral in the bribery than legitimacy conditions $(M \mathrm{~s}=7.7$ and 5.8 , respectively). The interaction indicated that although the means for both actors and observers were in the appropriate direction, observers $(M \mathrm{~s}=8.1$ and 4.8 , respectively) demonstrated a greater differentiation between the bribery and legitimacy instructions than did the actors $(M \mathrm{~s}=7.3$ and 6.7 , respectively). Indeed, some actors anecdotally reported during the debriefing that if the speech raters had felt that the payment was perfectly legitimate, they would not have mentioned anything at all about it on the rating sheet. Thus the actors' involvement in the situation and possible concern about how their actions were viewed by the note-sending audience may have prompted them to be somewhat sensitized to the morality issue by even the legitimate statement; naturally, the uninvolved observers would not share these concerns. (Indeed, the observers rated the legitimate note as being more moral than did the actors, $p<.04)$.

Attitudes toward seat belts. Actors were asked to express their own attitudes and observers were asked for their perceptions of the actors' attitudes on (a) the 13-point agree-disagree item used in the first two experiments and (b) the 16 bipolar adjective items that showed the strongest evaluative loading in the first two experiments. Both measures revealed a main effect of role, $F_{\mathrm{S}}(1$, $208)=73.42$ and 93.14, respectively, $p \mathrm{~s}<$ 
Table 4

Actors' and Observers' Perceptions of Actors' Attitudes Toward Seat Belts: Experiment 3

\begin{tabular}{|c|c|c|c|c|c|}
\hline \multirow[b]{3}{*}{ Item and condition } & \multicolumn{4}{|c|}{ Condition } & \multirow[b]{3}{*}{ Control } \\
\hline & \multicolumn{2}{|c|}{$\begin{array}{l}\text { High self-presentational } \\
\text { concern }\end{array}$} & \multicolumn{2}{|c|}{$\begin{array}{l}\text { Low self-presentational } \\
\text { concern }\end{array}$} & \\
\hline & Legitimate & Bribe & Legitimate & Bribe & \\
\hline $\begin{array}{l}\text { Agree-disagree item } \\
\text { Actor }\end{array}$ & & & & & 4.4 \\
\hline$\$ .50$ & 4.3 & 3.6 & 4.2 & 5.5 & \\
\hline$\$ 2.50$ & 4.6 & 6.5 & 5.6 & 3.9 & \\
\hline \multicolumn{6}{|l|}{ Observer } \\
\hline$\$ .50$ & 9.4 & 8.2 & 8.5 & 5.1 & \\
\hline$\$ 2.50$ & 9.1 & 8.9 & 8.4 & 9.1 & \\
\hline \multicolumn{6}{|l|}{ Actor } \\
\hline$\$ .50$ & 1.7 & 1.2 & 1.4 & 2.0 & \\
\hline$\$ 2.50$ & 2.0 & 2.1 & 1.8 & 1.6 & \\
\hline \multicolumn{6}{|l|}{ Observer } \\
\hline$\$ .50$ & 4.0 & 3.7 & 4.1 & 1.8 & \\
\hline$\$ 2.50$ & 3.7 & 3.9 & 3.0 & 3.7 & \\
\hline
\end{tabular}

.001 , and a four-way interaction of role, payment magnitude, bribery emphasis, and selfpresentational concern, $F_{\mathrm{S}}(1,208)=6.65$ and 6.85 , respectively, $p s<.02$. Means for the items are presented in Table 4.

Considering the actors first, there was a significant simple three-way interaction between payment magnitude, bribery emphasis, and self-presentational concern on the agree-disagree item, $F(1,208)=4.32, p<.04$. Dissecting the interaction further, it was found that payment magnitude and self-presentational concern interacted for actors who received the bribery statement, $F(1,208)=$ $5.50, p<.02$, but not for actors who received the legitimate statement. As predicted, a direct relationship was found between payment magnitude and attitude change when bribery was emphasized and self-presentational concerns were high, $F(1,208)=2.96$, $p<.05$. Thus when actors had to present their attitudes to the speech raters who had accused them of being bribed, those receiving $\$ 2.50$ espoused relatively neutral attitudes toward seat belts, whereas those paid $\$ .50$ remained staunchly in favor of seat belts. Moreover, the actors in the $\$ 2.50 /$ bribe/high self-presentational concern condition were the only actors whose attitude statements differed significantly from those of the control subjects, $t(123)=2.59, p<.05 .^{5}$

Contrary to initial expectations, no signifcant effects were obtained for actors in the legitimate payment conditions. Despite the presence of high decision freedom, negative consequences, and small payment (Calder et al., 1973; Collins \& Hoyt, 1972), no significant inverse relationship was obtained. As evidenced by the actors' responses on the morality manipulation check, it is possible that the legitimacy note did not clearly dispel the actors' concerns about how their actions were viewed by the speech raters. Actors in the legitimacy condition may have been sufficiently apprehensive about moral evaluation to wipe out an inverse relationship but not sufficiently apprehensive to generate a direct relationship.

No evidence of attitude change was obtained when self-presentational concern was

\footnotetext{
- Analyses performed on only the data from the actors again revealed the three-way interaction, $F(1,104)=5.47, p<.03$, along with each of the reported significant simple effects. Thus deleting the observers' responses has no effect on the results.
} 
Table 5

Interpretations of the Monetary Payment

\begin{tabular}{|c|c|c|c|c|}
\hline \multirow[b]{3}{*}{ Dependent variable } & \multicolumn{4}{|c|}{ Condition } \\
\hline & \multicolumn{2}{|c|}{ Actors } & \multicolumn{2}{|c|}{ Observers } \\
\hline & $\$ .50$ & $\$ 2.50$ & $\$ .50$ & $\$ 2.50$ \\
\hline Performed speech for the experimenter & 15.1 & $14.3_{\mathrm{a}}$ & $14.2_{b}$ & $11.4_{\Omega, b}$ \\
\hline Performed speech for the money & $.3_{\mathrm{a}, \mathrm{b}}$ & $2.3_{\mathrm{a}, \mathrm{c}}$ & $2.2_{\mathrm{b}, \mathrm{d}}$ & $6.2_{\mathrm{c}, \mathrm{d}}$ \\
\hline Money offered as a bribe & 3.5 & $4.7_{\mathrm{a}}$ & $4.2 b$ & $8.3_{n, b}$ \\
\hline Money offered to do a good job & $1.4_{\mathrm{n}}$ & $6.5_{\mathrm{n}}$ & $3.6_{\mathrm{b}}$ & $6.9 \mathrm{~b}$ \\
\hline Evaluation of the money & 3.1 & 2.8 & 4.0 & 3.5 \\
\hline
\end{tabular}

Note. Means within each row with a common subscript represent significantly different orthogonal comparisons via simple effects tests, $p<.05$. Higher means indicate greater amounts of the dependent variable (i.e., the spech was performed more for the experimenter or more for the money, the money was offered more as a bribe or more to do a good job, or there was a more positive evaluation of the money).

Iow. Although a slight inverse relationship was suggested when self-presentational concerns were low and bribery was emphasized, it did not approach significance $(p>.15)$. Such an effect, had it been significant, would have supported Rosenberg's (1965) hypothesis.

The actors' average ratings of seat belts on the bipolar adjectives revealed a pattern similar to that described above, but the effects were not as pronounced. None of the actor conditions differed significantly from the control group or from any other condition.

The observers' perceptions of the actors' attitudes failed to track the actors' reported attitudes. The main effect of role obtained on both attitude measures indicated that the observers thought the actors were in much greater agreement with the anti-seat-belt speeches than the actors actually were. By and large, the actors' behavior engulfed the field (Heider, 1958; Jones \& Harris, 1967), an effect that may have been aided by the high choice that was provided prior to agreement. The exception to this effect occurred for the observers in the $\$ .50 /$ bribe/low selfpresentational concern condition, who closely matched their yoked actors' attitudes. These observers differed on every orthogonal comparison from other observer conditions ( $p s<$ .01 ), and the simple two-way interactions in which the condition was embedded were significant $(p s<.03)$. These observers may have believed that accusing the actors of being bribed by a niggardly $\$ .50$ was an affront the actors would react against by expressing negative attitudes toward the topic, at least when the actors were provided with anonymity in the low self-presentational concern condition. No other significant effects were obtained for the observers.

Interpretations of the payment. Five items assessed interpretations of the payment: (a) "To what degree did you (the subject) agree to do the speech to accommodate the experimenter?", (b) "To what degree did you (the subject) agree to do the speech for the money?", (c) "How did you interpret the offer of the money?" (scale end points were labeled "totally as a bribe" and "not at all as a bribe"), (d) "To what degree do you believe that the money was given to you (the subject) to encourage you (him/her) to do a good job on the speech?", and (e) the average of three 7-point bipolar adjective scales that asked for ratings of the money: deserved-undeserved, honest-dishonest, and earned-unearned. Main effects of role, $F_{\mathrm{S}}(1$, $208)=13.09,39.98,8.79,4.11$, and 17.15, respectively, $p s<.05$, were obtained on each of the items, and a Role $\times$ Payment Magnitude interaction was obtained on the first three items, $F_{\mathrm{S}}(1,208)=3.46, \quad p<.06$; $5.68, p<.05$; and $4.35, p<.05$, respectively. No other effects were significant. Item means for the four Role $\times$ Payment Magnitude conditions are presented in Table 5.

As can be seen in the Table 5, compared to 
their observers, actors who received $\$ 2.50$ said they did the speech more for the experimenter, less for the money, believed the money was less of a bribe, and rated the money slightly less positively. The most striking difference between actors and observers was obtained on the bribe item, on which actors who received $\$ 2.50$ did not differ from either the actors or the observers in the $\$ .50$ conditions, but differed dramatically from the observers in the $\$ 2.50$ condition. These results, like those of the first two experiments, again suggest that the actors were motivated to interpret the large payment in socially desirable ways and to avoid the onerous implications of having been bribed to perform a task that had negative consequences.

Harm. If actors were concerned about the appearance of producing negative consequences, it could be expected that they should attempt to minimize the potential harmfulness of their speeches, at least relative to observers. Indeed, a role main effect, $F(1,208)$ $=5.71, p<.02$, on the item, "How beneficial or harmful do you think your (the subject's) speech could be for listeners?" indicated that actors stated their speeches were less harmful than the observers believed them to be ( $M \mathrm{~s}=$ 9.8 and 10.8 , respectively).

Choice and responsibility. Responses to the item, "How much choice did you (the subject) have in deciding on which side of the topic, pro or con, to write an essay and deliver a speech?" revealed a main effect for role, $F(1,208)=5.56, p<.02$, and a Payment Magnitude $\times$ Bribery Emphasis interaction, $F(1,208)=6.16, p<.02$. Actors reported greater choice than the observers ascribed to them $(M \mathrm{~s}=7.6$ and 5.9 , respectively). The interaction supports Kelley's (1967) analysis of attributions under varying payment magnitude and legitimacy conditions. An inverse relationship appeared between payment magnitude and choice when the legitimate comment was made $(M \mathrm{~s}=$ 8.1 and 6.3 for the small and large payment conditions, respectively), but a direct relationship occurred when the bribery comment was made ( $M \mathrm{~s}=5.5$ and 7.2 , respectively). Large payments accepted when illegitimate forces were salient permitted high choice to be ascribed to the actor (Kelley, 1967).
As in the first two experiments, an item that asked how responsible the actors were for any persuasive consequences of their speech failed to reveal significant effects. Given the above pattern on the choice item, it seems likely that subjects did not directly equate choice with the term responsibility, perhaps because they did not attach the same meaning to the latter term that theorists do.

Speech performance. Ratings of how well the actors performed the speech revealed a main effect of role, $F(1,208)=31.12, p<$ .001 , and a Role $\times$ Payment Magnitude $\times$ Self-Presentational Concern interaction, $F(1$, $208)=4.86, p<.03$. Actors believed that they did a poorer job on the speech than did observers ( $M \mathrm{~s}=8.3$ and 10.6, respectively). The interaction, as well as a comparable interaction obtained on the average bipolar adjective ratings of the quality of the speeches, $F(1,208)=4.02, p<.05$, does little to clarify any of the preceding effects. The major finding was that actors in the $\$ .50 /$ low self-presentational concern condition rated their speeches and their performances more favorably than other actors rated theirs. Despite these high ratings, however, these actors did not demonstrate significant attitude change: Perceptions of superior speech quality were not sufficient to produce attitude change.

\section{Discussion}

As predicted, a direct relationship was obtained between payment magnitude and attitude change when moral evaluation was heightened by the bribery accusation and actors had to report their attitudes to the accusing audience. The effect supports the interpretation that subjects whose identities are threatened by the appearance of bribery will account for their actions by attempting to show that they are not in disagreement with the nature of the action and did not perform it solely to get a large payment. In addition, actors who received the large payment, as compared with their observers, said that the payment was less valuable, emphasized that they did the speech more for the experimenter and less for the money, and proclaimed that the money was less of a 
bribe. These actions suggest the attempt to interpret the large payment in a way that avoids the appearance of monetary gain as a primary motive for their actions.

Although the legitimacy condition was intended to dispel the negative aspects of moral evaluation for the actors, it was apparently not completely successful in doing so. The observers believed that the actors were more favorably evaluated by the speech raters in the legitimacy condition than in the bribe condition, attesting to the success of the manipulation when viewed by uninvolved bystanders. But the involved actors did not display as pronounced a difference between these conditions on the manipulation check. Perhaps the combination of the extreme nature of the actors' actions (persuading younger pupils to avoid the use of seat belts) and the fact that they received an audience's note mentioning their monetary payment produced an intermediate degree of moral evaluation for actors in the legitimacy condition. That is, it may have been high enough to wipe out an inverse relationship, but not sufficiently high (at least as compared with actors who were explicitly accused of being bribed) to generate a direct relationship. In Experiment 1, the inverse relationship was clearly obtained when moral evaluation was low, but those subjects did not receive an explicit note from the audience that mentioned money and were further distracted from moral evaluation by the statement about the observer's different focus.

Attitude change was obtained only when self-presentational concerns were high. Although it was predicted that the effects of the independent variables would be more pronounced under high than low self-presentational concern conditions, it was not necessarily anticipated that low concerns would wipe out effects. Symbolic interactionists propose that once people learn and incorporate the rules society applies when judging behaviors, they use these "personal" standards to judge their own actions irrespective of whether a real audience is present (although accounting should be greater before a real audience than when one is alone). Inappropriate behaviors produce feelings of guilt, self-doubt, anxiety, or embarrassment, all of which people attempt to reduce. In this sense, people can be said to be concerned with selfpresentations even in private, so long as their attention is focused on themselves as social objects vis-à-vis an imagined audience (Schlenker, 1980). Such private self-presentation would generate self-serving interpretations of situations and should produce relatively enduring attitude change.

In the present study, though, genuine attitude change did not seem to occur, at least in the sense that no attitude change effects were found when the actors were free to anonymously fill out the questionnaire for an audience that supposedly was unaware of the nature of the predicament. On the surface, then, the results might appear to support the arguments of those who contend that no genuine attitude change occurs in the forced compliance paradigm (Gaes, Kalle, \& Tedeschi, 1978).

Such a conclusion, however, would be a premature overgeneralization. There are theoretical reasons to assume that genuine attitude change sometimes occurs and sometimes does not occur in predicaments (Schlenker, 1980). People sometimes tell blatant lies to extricate themselves from predicaments, privately label the account a lie, and never come to believe a word of what they say. On the other hand, less blatantly deceptive accounts might be employed for self-presentational purposes and end up being believed by the actor because they fit, at least roughly, the existing facts as the actor knows them (Jones \& Wortman, 1973; Schlenker, 1980).

Although the precise conditions that govern the occurrence of such genuine attitude change are not completely understood, a hypothesis can be offered. Any factor that prevents the actor from labeling a public statement a lie should maximize the likelihood of internalization (Schlenker, 1980). For instance, if a self-serving account of a predicament is greatly discrepant from actors' initial private beliefs about themselves and the event, they should label the account as a lie designed to fool a real audience: It should not be internalized. However, if a self-serving account is only slightly to moderately discrepant from actors' initial beliefs, they should label it as the truth and privately 
believe that it accurately describes the event. Similarly, if a knowledgeable audience familiar with the event accepts the account as truthful, the actors should be more likely to internalize it.

In the present study, arguing against the use of seat belts might have been sufficiently discrepant from subjects' private beliefs that their accounts were labeled as necessary but inaccurate. Likewise, Gaes et al. (1978) had subjects argue against toothbrushing, a topic that also should be greatly discrepant from private beliefs. Future research might be better directed toward the examination of the conditions under which genuine attitude change occurs, instead of attempting to show that genuine attitude change either does or does not always occur in forced compliance settings.

\section{General Discussion}

The data from the three studies suggest that interpersonal concerns can be quite salient to subjects who are placed in a typical forced compliance situation. Subjects do seem to use attitude statements as a means of justifying and legitimizing their actions when they confront social predicaments in which their desired identities are threatened. Whether such accounting tactics result in an inverse or direct relationship between payment magnitude and attitude expressions depends on whether the individual perceives moral evaluation in the situation to be low or high. When moral evaluation is seen as high, a direct relationship is obtained, at least when subjects must account to an audience that observed the predicament. Such a relationship was obtained in Experiments 2 and 3 and suggested in Experiment 1. In addition, subjects who receive large payments under conditions of high moral evaluation attempt to interpret the payment in ways that make it appear more legitimate (Experiments 1 and 3 ). In contrast, when moral evaluation is low, an inverse relationship occurs (Experiment 1).

The results of the three experiments can also be examined within the theoretical frameworks of dissonance theory, self-perception theory, and incentive theory. Considering dissonance theory first, it appears that the degree to which the theory can explain the data depends largely on which interpretation of the theory is employed. According to the original formulation of the theory, the counterattitudinal action should have been highly dissonant when payment (justification) was small. All of the factors implicated in the arousal of dissonance were maximized in the $\$ .50$ cells of Experiments 1 and 3 and in the \$.50/agreement cell of Experiment 2: Subjects freely chose to make a potentially harmful speech, received minimal monetary justification, and the money was introduced in a manner that should have affected their decisions (explicitly so in the agreement condition of Experiment 2). Yet a significant direct relationship was obtained in the agreement condition of Experiment 2 and in the bribery condition of Experiment 3, and this relationship was suggested in the high moral evaluation condition of Experiment 1 .

For some dissonance theorists (e.g., Carlsmith \& Freedman, 1968), factors introduced after people freely decide to behave counterattitudinally should not affect dissonance magnitude. In this case, the moral evaluation manipulations of Experiments 1 and 3 should have had no effects on dissonance, yet these manipulations clearly were instrumental in generating a direct relationship. Aronson's (1968) revision of dissonance theory contends that dissonance is generated by discrepancies between one's self-concept and behavior. A reasonable derivation of this approach might suggest that dissonance should be greatest (resulting in a strong inverse effect) when payment is small and moral evaluation is high, since discrepancies between important aspects of one's self-concept and one's actions are then most clearly evident. Yet a direct relationship appeared in these cases. Thus the above "straightforward" derivations of dissonance theory were not supported.

However, there are two other possible dissonance interpretations that may account for the obtained results. First, one might assume that the experimenter's request was the major force for inducing the subjects' compliance (even though the money was offered as part of the request and subjects agreed to perform the counterattitudinal action only after it was 
clear that they would receive the payment). Although such an assumption has usually not been made in prior dissonance studies, it is at least plausible. One must also assume that events occurring after dissonance has been aroused will affect dissonance magnitude. Given these assumptions, the introduction of "legitimate" money to the request constitutes a consonant cognition and reduces dissonance in relation to its magnitude. If, on the other hand, the money is made to appear to be a bribe, it generates an additional dissonant cognition and increases dissonance in relation to its magnitude.

Second, one could reconceptualize the possible locus of dissonance in the present studies by focusing on different cognitions in different cells. One could say that dissonance is generated by the cognitions, "I am a truthful, moral person who doesn't tell harmful lies," and "I just told a harmful lie" (Aronson, 1968), and that these cognitions were engaged in the low moral evaluation conditions of Experiment 1, producing an inverse relationship. But dissonance also might be generated by the cognitions, "I am a moral person who doesn't accept bribes" and "I just accepted a bribe for an immoral action." This pair of cognitions could lead subjects to change their attitudes more the greater the magnitude of the payment (bribe) and could have been engaged under the conditions that generated the direct relationships. Naturally, these derivations would produce another "evolved" form of dissonance theory (Greenwald \& Ronis, 1978) that gets even further away from the concept of cognitive inconsistency. This evolved form would focus almost exclusively on how people protect their self-esteem and social identity when these are threatened in real or imagined social interactions. In fact, the kinds of predictions typically made by dissonance theorists can be reconceptualized as a "special case" of the more general social identity approach (Schlenker, 1978, 1980). Such a possibility has been indirectly suggested by Zimbardo (1969, p. 15), who argued that dissonance theory "may be subservient to more basic phenomena which characterizes this approach as a 'face-saving theory.'"

In any event, it is clear that there are a surprising number of possible dissonance theory derivations that can be applied to the data. At the very least, it can be said that there is nothing in dissonance theory to suggest that money or other inducing forces can become dissonant cognitions under certain conditions. Thus the present results also could be interpreted as extending basic dissonance theory ideas.

Self-perception theory (Bem, 1972) would seem to have predicted an inverse relationship in all three experiments (particularly in the agreement condition of Experiment 2, in which the payment was explicitly introduced in a way that was relevant to the descision to perform the behavior). The fact that the direct relationship consistently appeared raises doubts that subjects were simply inferring their attitudes from their behavior. Additionally, it is not clear how self-perception theory would explain the discrepancies between the attributions made by the experimental subjects and the observers or the fact that the observers failed to track the actors' attitudes in Experiment 3. An extension of self-perception theory that incorporates the notion of self-awareness (Wegner \& Finstuen, 1977 ) predicts a dissonance-like inverse relationship when subjects are objectively selfaware (focus on self) and an incentive-like direct relationship when subjectively selfaware (focus on the environment), but these predictions were not supported either. Objective self-awareness should have been high in all conditions, given the presence of the observation mirror and videocamera, yet the direct relationship was still obtained.

The data could be partially reconciled with self-perception theory if one accepts the hypothesis that choice should be inversely related to payment magnitude when legitimate forces are salient and directly related to payment magnitude when illegitimate forces are salient. The choice data from Experiment 3 support this hypothesis. When choice is high, subjects should infer their attitudes on the basis of their behavior. Even so, it is difficult for self-perception theory to explain why attitude change occurred in Experiment 3 only when subjects believed their responses would be shown to the audience that accused them of being bribed. Further, the discrepan- 
cies between the actors' and observers' attributions would still be unexplained by the theory.

Finally, incentive theory predicted a direct relationship when payment was offered as an incentive for a high quality performance (performance condition of Experiment 2). Indeed, subjects paid $\$ 2.50$ in the performance condition stated that they did a superior job on their speeches. Yet the direct relationship was obtained only in the agreement condition, where no performance quality differences were obtained. Further, Rosenberg's (1965) prediction of an inverse relationship when subjects experience high evaluation apprehension was not supported. Evaluation apprehension should have been particularly high when subjects were accused of being bribed in Experiment 3, yet the direct relationship occurred.

It might be argued that the present experiments provided tests of the conditions that govern self-presentational behavior, but the experiments are fundamentally different from prior studies in the forced compliance arena, since it is not clear that genuine attitude change was obtained. According to such an argument, the present studies would have few or no implications for research and theory in the area. There seem to be several flaws in this argument. First, a surprising proportion even of recent studies in the forced compliance area have employed measures of attitudes that could be readily used by subjects for self-presentation purposes. A survey of 25 forced compliance studies that appeared in the Journal of Personality and Social Psychology and the Journal of Experimental Social Psychology from 1970 through 1978 showed that only seven clearly made an attempt to make subjects' postexperimental attitude responses anonymous, thus reducing the likelihood that subjects' responses would be affected by concerns about their public identities. The rest either made no such attempt (many explicitly asked subjects to sign their names to the attitude questionnaire) or did not provide sufficient information in the article to determine the conditions that surrounded the responses. Thus much of the existing forced compliance literature does not allow one to differentiate clearly between "genuine attitude change" and public self-presentation.

Second, the conditions that existing theories (dissonance, self-perception, incentive) propose as necessary and sufficient for the occurrence of attitude change were present in the present studies. Further, effects occurred that in isolation might have been labeled as manifestations of "dissonance" or "self-perception." Given this fact, it is difficult to argue that the present results are irrelevant to the area without also calling into question aspects of the existing theoretical knowledge.

Finally, it should be stressed that we are not suggesting that all attitude change following the performance of counterattitudinal behavior represents nothing but a public impression management strategy. As previously mentioned, there are reasons to believe that subjects' attitude expressions in the forced compliance paradigm are sometimes genuine but sometimes meant to influence or impress an audience. Future research should consider the conditions under which the accounts people use for their actions are privately recognized as "con jobs" of others or are actual internalized attitudes.

\section{Reference Notes}

1. Schlenker, B. R. Translating actions to attitudes. Grant proposal, 1977. (Department of Psychology, University of Florida, Gainesville, Fl. 32611.)

2. Shaw, M. E. Personal communication, November 26, 1976.

\section{References}

Alexander, C. N., Jr., \& Knight, G. W. Situated identities and social psychological experimentation. Sociometry, 1971, 34, 65-82.

Aronson, E. Dissonance theory: Progress and problems. In R. Abelson et al. (Eds.), Theories of cognitive consistency: A sourcebook. Chicago: Rand McNally, 1968.

Bem, D. J. Self-perception theory. In L. Berkowitz (Ed.), Advances in experimental social psychology. New York: Academic Press, 1972.

Calder, B. J., Ross, J., \& Insko, C. A. Attitude change and attitude attribution: Effects of incentive, choice, and consequences. Journal of Personality and Social Psychology, 1973, 25, 8499.

Carlsmith, J. M., Collins, B. E., \& Helmreich, R. L. Studies in forced compliance: I. The effect of pressure for compliance on attitude change produced by face-to-face role playing and anony- 
mous essay writing. Journal of Personality and Social Psychology, 1966, 4, 1-13.

Carlsmith, J. M., \& Freedman, J. L. Bad decisions and dissonance: Nobody's perfect. In R. Abelson et al. (Eds.), Theories of cognitive consistency: A sourcebook. Chicago: Rand McNally, 1968.

Collins, B. E., \& Hoyt, M. F. Personal responsibilityfor-consequences: An integration and extension of the "forced compliance" literature. Journal of $E_{x-}$ perimental Social Psychology, 1972, 8, 558-593.

Cooper, J., \& Worchel, S. Role of undesired consequences in arousing cognitive dissonance. Journal of Personality and Social Psychology, 1970, 16, 199-206.

Crano, W. D., \& Messé, L. A. When does dissonance fail? The time dimension in attitude measurement. Journal of Personality, 1970, 38, 493-508.

Elms, A. C. Role playing, incentive, and dissonance. Psychological Bulletin. 1967, 68, 132-148.

Elms, A. C., \& Janis, I. L. Counter-norm attitudes induced by consonant versus dissonant conditions of role-playing. Journal of Experimental Research in Personality, 1965, 1, 50-60.

Epstein, S. The self-concept revisited: Or a theory of a theory. American Psychologist, 1973, 28, 404416.

Festinger, L. A theory of cognitive dissonance. Evanston, Il.: Row, Peterson, 1957.

Fishbein, M., \& Ajzen, I. Belief, attitude, intention and behavior: An introduction to theory and research. Reading, Mass.: Addison-Wesley, 1975.

Gaes, G. G., Kalle, R. J., \& Tedeschi, J. T. Impression management in the forced compliance situation. Two studies using the bogus pipeline. Journal of Experimental Social Psychology, 1978, 14, 493-510.

Gerard, H. B. Compliance, expectation of reward, and opinion change. Journal of Personality and Social Psychology, 1967, 6, 360-364.

Gerard, H. B., Conolley, E. S., \& Wilhelmy, R. A. Compliance, justification, and cognitive change. In L. Berkowitz (Ed.), Advances in experimental social psychology. New York: Academic Press, 1974.

Greenwald, A. G., \& Ronis, D. L. Twenty years of cognitive dissonance: Case study of the evolution of a theory. Psychological Review, 1978, 85, 5357.

Heider, F. The psychology of interpersonal relations. New York: Wiley, 1958.

Helmreich, R. L., \& Collins, B. E. Studies in forced compliance: Commitment and magnitude of inducement to comply as determinants of opinion change. Journal of Personality and Social Psychology, 1968, 10, 75-81.

Holmes, J. G., \& Strickland, L. H. Choice freedom and confirmation of incentive expectancy as determinants of attitude change. Journal of Personality and Social Psychology, 1970, 14, 39-45.

Hoyt, M. F., Henley, M. D., \& Collins, B. E. Studies in forced compliance: The confluence of choice and consequences on attitude change. Journal of Personality and Social Psychology, 1972, 22, 1-7.
Janis, I. L., \& Gilmore, J. B. The influence of incentive conditions on the success of role-playing in modifying attitudes. Journal of Personality and Social Psychology, 1965, 1, 17-27.

Jones, E. E., \& Harris, V. A. The attribution of attitudes. Journal of Experimental Social Psychology, 1967, 3, 1-24.

Jones, E. E., \& Wortman, C. Ingratiation: An attributional approach. Morristown, N. J.: General Learning Press, 1973.

Kaufmann, D. R. Incentive to perform counterattitudinal acts: Bribe or gold star? Journal of Personality and Social Psychology, 1971, 19, 8291.

Kelley, H. H. Attribution theory in social psychology. In D. Levine (Ed.), Nebraska symposium on motivation (Vol. 15). Lincoln: University of Nebraska Press, 1967.

Kelman, H. C., \& Baron, R. M. Inconsistency as a psychological signal. In R. P. Abelson et al. (Eds.), Theories of cognitive consistency: A sourcebook. Chicago: Rand McNally, 1968.

Kelman, H. C., \& Baron, R. M. Moral and hedonic dissonance: A functional analysis of the relationship between discrepant action and attitude change. In S. Himmelfarb \& A. H. Eagly (Eds.), Readings in attitude change. New York: Wiley, 1974.

Linder, D. E., Cooper, J., \& Jones, E. E. Decision freedom as a determinant of the role of incentive magnitude in attitude change. Journal of Personality and Social Psychology, 1967, 6, 245-254.

Lyman, S. M., \& Scott, M. G. A sociology of the absurd. New York: Appleton-Century-Crofts, 1970.

Nel, E., Helmreich, R., \& Aronson, E. Opinion change in the advocate as a function of the persuasibility of his audience: A clarification of the meaning of dissonance. Journal of Personality and Social Psychology, 1969, 12, 117-124.

Nuttin, J. M., Jr. The illusion of attitude change: Toward a response contagion theory of persuasion. New York: Academic Press, 1975.

Riess, M., \& Schlenker, B. R. Attitude change and responsibility avoidance as modes of dilemma resolution in forced compliance settings. Journal of Personality and Social Psychology, 1977, 35, 21-30.

Rosenberg, M. J. When dissonance fails: On eliminating evaluation apprehension from attitude measurement. Journal of Personality and Social Psychology, 1965, 1, 28-42.

Schlenker, B. R. Self-image maintenance and enhancement: Attitude change following counterattitudinal advocacy. Proceedings of the 81st Annual Convention of the American Psychological Association, 1973, 8, 271-272.

Schlenker, B. R. Attitudes as actions: Social identity theory and consumer research. Advances in Consumer Research, 1978, 5, 352-359.

Schlenker, B. R. Impression management: The selfconcept, social identity, and interpersonal relations. Belmont, Calif.: Brooks/Cole, 1980.

Schlenker, B. R., \& Schlenker, P. A. Reactions fol- 
lowing counterattitudinal behavior which produces positive consequences. Journal of Personality and Social Psychology, 19.75, 31, 962-971.

Sherman, S. J. Effects of choice and incentive on attitude change in a discrepant behavior situation. Journal of Personality and Social Psychology, 1970, 15, 245-252.

Steiner, I. D. Perceived freedom. In L. Berkowitz (Ed.), Advances in experimental social psychology. New York: Academic Press, 1970.

Tedeschi, J. T., Schlenker, B. R., \& Bonoma, T. V. Cognitive dissonance: Private ratiocination or public spectacle? American Psychologist, 1971, 26, 685-695.

Verhaeghe, H. Mistreating other persons through simple discrepant role playing: Dissonance arousal or response contagion. Journal of Personality and Social Psychology, 1976, 34, 125-137.

Wegner, D. M., \& Finstuen, K. Observers' focus of attention in the simulation of self-perception. Journal of Personality and Social Psychology, $1977,35,56-62$.

Wicklund, R. A., \& Brehm, J. W. Perspectives on cognitive dissonance. Hillsdale, N.J.: Erlbaum, 1976.

Zimbardo, P. G. The cognitive control of motivation: The consequences of choice and dissonance. Glenview, Ill.: Scott, Foresman, 1969.

Received April 9, 1979 